\title{
Los filántropos de Camus y Unamuno: el Dr. Rieux y San Manuel Bueno, Mártir
}

Por: M. L. Alí Víquez Jiménez ${ }^{1}$, Universidad de Costa Rica

Fecha de recibido: 14 de noviembre, 2016.

Fecha de aceptación: 3 de marzo, 2017

\section{Resumen}

En este artículo se comparan dos personajes caracterizados por sus quehaceres comprometidos con el bien de los otros: don Manuel (Unamuno, San Manuel bueno, mártir) y el Dr. Bernard Rieux (Camus, La peste). Se exploran las afinidades filosóficas que los unen tanto como una serie de diferencias de la misma naturaleza.

\section{Abstract}

\section{THE PHILANTROPISTS OF CAMUS AND UNAMUNO: DR RIEUX AND SAINT MANUEL BUENO, MARTYR}

This article compares two characters who represent deeds committed with the wellbeing of others: Manuel (Unamuno, Saint Manuel bueno, martyr) and Dr. Bernard Rieux (Camus, La peste). The philosophical affinities which pair them with a series of differences of the same nature are explored.

1 Alí Víquez Jiménez es Magíster Litterarum, graduado de la Universidad de Costa Rica, y un destacado docente e investigador de esa casa de estudios superiores. Ha sido galardonado con los premios más prestigiosos de la literatura de su país, y reconocido como uno de los autores de lectura obligatoria, por el Ministerio de Educación Pública. Se desempeña como docente e investigador en la Universidad de Costa Rica. Contacto: aliviquezj@gmail.com.

Alí Víquez Jiménez. Los filántropos de Camus y Unamuno: el Dr. Rieux y San Manuel Bueno, Mártir. Revista Comunicación. Año 38 , volumen 26, número 1, enero - junio, 2017. Instituto Tecnológico de Costa Rica. ISSN: 0379-3974 / e-ISSN: 1659-3820.
PALABRAS CLAVE:

Albert Camus, Miguel de Unamuno,

Literatura española contemporánea,

literatura francesa contemporánea, literatura

comparada, novela europea.

KEY WORDS:

Albert Camus, Miguel de Unamuno, Spanish literature, Spanish contemporary literature, French contemporary literature, comparative literature, European novel. 


\section{INTRODUCCIÓN}

Tras examinar a los misántropos en Camus y Greene(Víquez, 2016), ahora pondré mi atención en los filántropos de Camus y Unamuno ${ }^{2}$. Corro el riesgo de que, como pasa a menudo en la literatura, el examen hecho de los "personajes oscuros" resulte mucho más atractivo que el que ahora emprendo acerca de los "luminosos". ¿Quién duda, por ejemplo, que Iván Karamázov y Stavroguin son personajes más apasionantes que Aliosha Karamázov o el príncipe Mishkin?3 Espero al menos que este nuevo ensayo revele una complejidad pareja de los filántropos y los misántropos, si bien estos últimos podrían capturar más la atención.

Quizás resulta extraño que quienes albergan el odio y el desprecio al parecer se impongan en el aprecio de los lectores, antes que quienes aman a sus semejantes y hasta se sacrifican por estos. Pero puedo comenzar explicándolo desde Machado (1999): el hecho es que la filantropía es un secreto, algo que pocos, poquísimos, conocen; en tanto, la misantropía es moneda común: "Converso con el hombre/ que siempre va conmigo (...) que me enseñó el secreto/ de la filantropía". Es necesario hacer un esfuerzo para entender a quienes creen que el ser humano es bueno y se merece el bien; pensar lo contrario no parece difícil ni raro, aunque a lo mejor mucha gente se avergüenza de hacerlo y no lo admitiría.

\section{SAN MANUEL BUENO, MÁRTIR}

Esta narración arranca con un epígrafe bíblico, de San Pablo: "Si solo en esta vida esperamos en Cristo, somos los más miserables de los hombres todos"

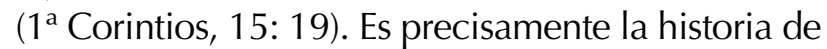
un cura de aldea en España, don Manuel, que no cree en la resurrección y es el hombre más miserable de todos. Es sencillo el planteamiento filosófico de la novela ${ }^{4}$ : don Manuel es un santo porque,

2 El Dr. Rieux es el protagonista y narrador de La peste (Camus, 1947) y San Manuel Bueno es el protagonista de "San Manuel Bueno, mártir” (Unamuno, 1931). Estas fechas corresponden a primeras ediciones.

$3 \quad$ Y eso por mucho que Dostoievski pretendiera lo contrario.

4 O más bien "nouvelle", pero no nos metamos demasiado en esto del subgénero, porque andamos en los terrenos de Unamuno y sus boutades al respecto: que si novela o nivola o sepa usted. sabiéndose así de miserable, hace todo lo que está a su alcance para que esa miseria no la comparta el pueblo de Valverde de Lucerna. Sabido es que Unamuno -al igual que Pablo de Tarsos- creía en la promesa de la vida eterna personal como el requisito indispensable de la felicidad humana; de aquí un personaje que, incrédulo ante tal prodigio de la imaginación y la fe religiosa, solo puede ser un desdichado ${ }^{5}$.

Fue este un punto en el que Unamuno no aceptaba la alternativa. Si no se tenía acceso a la vida eterna, tampoco se tenía acceso a ninguna felicidad en este mundo, así fuera pasajera o frágil ${ }^{6}$. El cura don Manuel es un personaje que no conoce ninguna clase de alegría; su estado depresivo lo lleva a los linderos del suicidio, según él mismo confiesa, como lo único que verdaderamente lo tienta, porque lo liberaría de una existencia que es un fardo de amargura. Es decir, como si la muerte total en el futuro tuviera el efecto obligatorio de enturbiar la existencia en el presente.

Don Manuel es un filántropo porque vive para ocultar a los miembros de su comunidad religiosa la verdad insoportable de la muerte total. Volteriano no tanto por asuntos políticos (por el temor de que se pierda un mecanismo para controlar a una plebe que sin el freno de Dios se podría volver inmanejable); karamasoviano no tanto por asuntos éticos (por el temor de que sin Dios "todo está permiti$\mathrm{do}^{\prime \prime}$ ). Más bien melancólico y compasivo: convencido de que la vida solo puede disfrutarse si se la cree eterna, decide engañar a todo el que se deje engañar sobre este punto para que los menos lúcidos que él consigan ser felices: "Dios no existe: hay que inventarlo" ${ }^{\prime 7}$. Actúa acaso siguiendo el ejemplo de Jesucristo, como el propio texto propone. Este se vale de una serie de apócopes para crear esta identificación entre don Manuel y Jesús ${ }^{8}$.

$5 \quad$ Alfredo Tamayo Ayestarán (2001) apunta un interesante paralelismo entre Unamuno y Nietzsche a propósito de este tema.

6 Recuérdese aquella aseveración tan suya y tan reiterada, de que él quería seguir siendo para siempre Miguel de Unamuno, hasta con sus mismos zapatos. Me pregunto si su zapatero también querría la inmortalidad personal. La bibliografía sobre este tema es abundante; véanse Baker (1991), Benítez (1968) y Caraway (1995).

7 No lo cito. Tampoco a Voltaire, ya que he suprimido el condicional.

8 Véanse Robert Baah (2003) y Godoy Gallardo (2001). 
Don Manuel se encuentra pues en las antípodas de quienes valorizan la existencia precisamente a causa de su carácter efímero. Toda la tradición del epicureísmo en procura del placer posible aunque fugaz le es ajena e incomprensible. También toda capacidad estética para celebrar la brevedad de la vida en versos como los de Machado (1999, p. 150): "Me gusta verlos pintarse/ de sol y grana volar, / bajo el cielo azul cantar / súbitamente y quebrarse.". Don Manuel es incapaz de apreciar una pompa de jabón. No entiende al Aquiles que afirma que los dioses inmortales envidian a los humanos, porque estos conocen el valor del presente de una forma que jamás podrá alguien que vive para siempre. Mucho menos entiende a Borges, que teme a la inmortalidad personal como el más severo castigo imaginable.

Puesto sobre este camino, que es casi como un estado de ánimo de profunda tristeza porque la vida humana no es eterna, don Manuel se propone ocultar su trágica verdad para no envenenar a los demás con su propio veneno. Mentirles. Y aquí resulta darse cuenta de que solo los más simples de los seres humanos se dejarán engañar. Blasillo el Bobo, el subnormal que recorre la aldea de Valverde de Lucerna, es aquel en quien no existe la más mínima objeción para creer en la ilusión de la inmortalidad personal pregonada por don Manuel. En cambio, con Lázaro, el inteligente hermano de la narradora, el embuste no resulta y don Manuel le confiesa en secreto que no cree en aquello que predica. Entre estos dos polos, la mayoría de los aldeanos tiende a parecerse a Blasillo el Bobo, de una manera que nos puede hacer sospechar la poca confianza de Unamuno en la capacidad intelectual del pueblo9.

Estamos ante un planteamiento filosófico que podríamos Ilamar "elitismo filantrópico" tanto como "incapacidad para el goce lúcido de lo inmediato". Para don Manuel, solo existe la posibilidad del goce de lo inmediato desde la falta de lucidez (y si nos atenemos a la forma en que Unamuno lo expresa en su personaje de Blasillo, diríamos que desde la imbecilidad), y ello convierte a un filántropo como él en el celoso guardián de la verdad, para que esta no llegue a oídos de la mayoría: “La verdad (...) es

9 Al menos, del pueblo religioso, que en la versión de este texto, es todo el pueblo. En cierto modo, es ofensivo con los creyentes. algo terrible, algo intolerable, algo mortal; la gente sencilla no puede vivir con ella." (Unamuno, 1987, p. 43). La inteligencia es el mal, para don Manuel y para Schopenhauer.

En esta línea de rechazo filantrópico de la inteligencia, don Manuel está dispuesto a ir muy lejos. No le interesa promover ninguna clase de progreso político ni educativo; aunque no se opone a ellos, solo los considerará con benevolencia cuando constituyan distracciones útiles para que la gente no fije sus ojos en la terrible verdad de la muerte. Su papel como sacerdote no es educar ni acrecentar la justicia: más bien, es un conservador convencido de que el futuro, cuanto menos cambie en relación con el presente, mejor será para todos los que logren continuar viviendo en una suerte de "felicidad medieval". Su posición política se exagera (aunque también se aclara) en esta cita: "Sí, ya sé que uno de esos caudillos de lo que llaman la revolución social ha dicho que la religión es el opio del pueblo. Opio... Opio... Opio... Sí, démosle opio, y que duerma y que sueñe." (Unamuno, 1987, p. 49) ${ }^{10}$.

Está dispuesto a procurarse a sí también una suerte de opio: "Yo mismo con esta mi loca actividad me estoy administrando opio." (Unamuno 1987, p. 49) El personaje vive imbuido en un torbellino de quehaceres que le procuran el olvido de la verdad que lo atormenta. Así, su constante dedicación al cuido de enfermos, misas, caridades, tanto como a otras labores menos propias de un sacerdote, como dar clases en la escuela o hasta ayudar en las labores del campo, tiene la doble finalidad de servir como ayuda al prójimo y como opio para sí mismo. La filantropía de don Manuel no es teórica: ama a los demás colaborando de manera concreta en la resolución de sus necesidades prácticas. Pero también es importante mencionar que está enmarcada en un propósito global y mayor: ama a los demás, tratando de engañarlos en cuanto al sinsentido de una existencia cuyo destino es la muerte. Lázaro lo dice: "...es demasiado inteligente como para creer todo lo que tiene que enseñar." (Unamuno, 1987, p. 39) Por eso quiere que los otros se ocupen de lo práctico y concreto tanto como él lo hace, porque así se

10 Para una aproximación precisa a las implicaciones políticas de esta novela, véase Fagan (2009). Ahí se demuestra que Unamuno era mucho menos reaccionario al final de su vida de lo que esta cita aislada podría sugerir si se la ve fuera de contexto. 


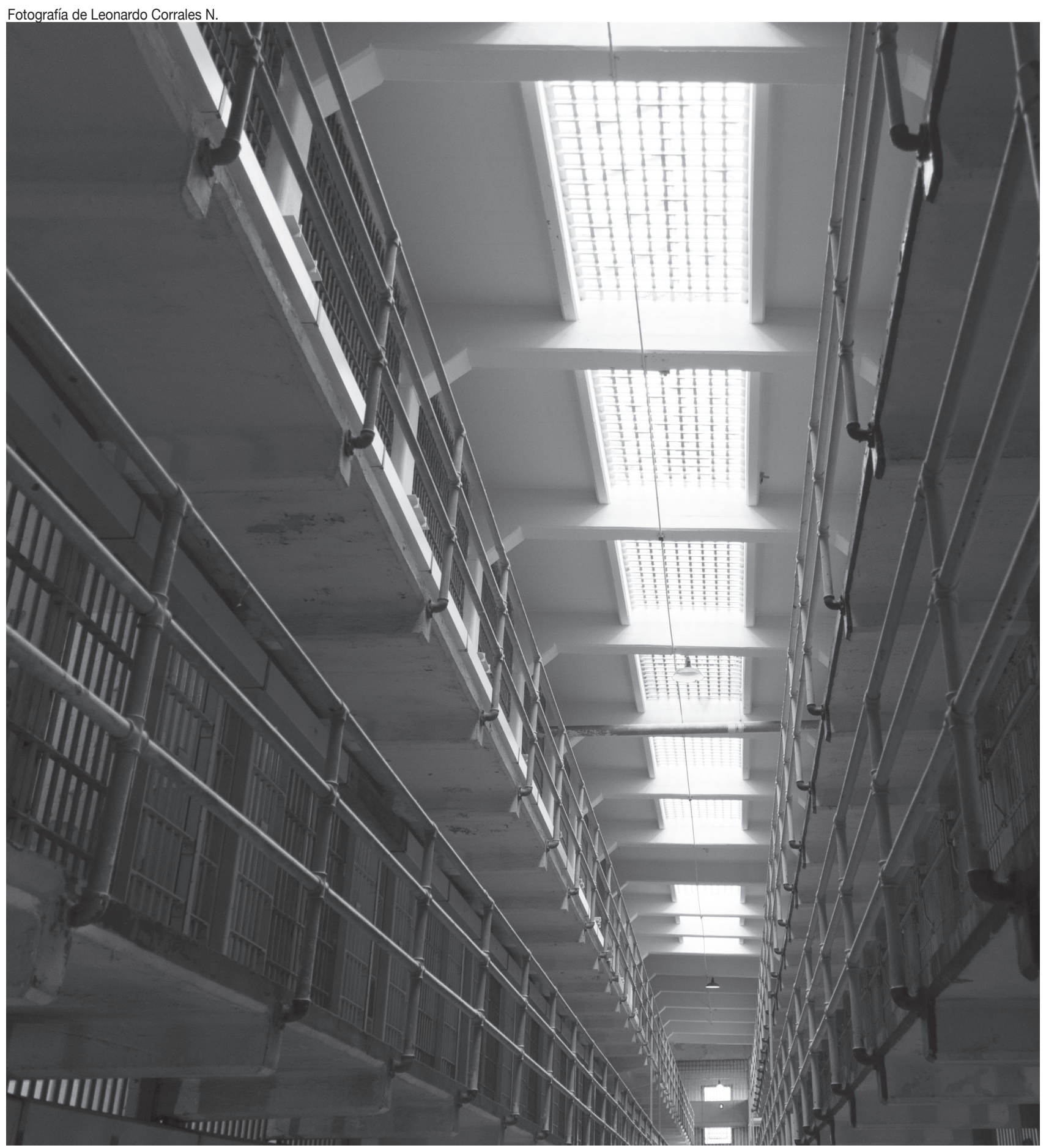

alejarán del peligro de pensar demasiado y acaso darse cuenta de lo que él ya sabe sobre la muerte.

Además, la filantropía de don Manuel, como actividad concreta, es lo que -más mal que bien- lo aleja de la desesperación. Su opio no le funciona del todo, pero estaría peor de no tomarlo.
La narración está en boca de Ángela, de cuyas luces también se puede dudar ${ }^{11}$. Escribe esta historia sin darse cuenta de que está denunciando al cura (a quien, tras la muerte, busca el obispo beatificar). Hay algo — sin embargo_- más profundo en ella:

11 Sobre la forma en que Ángela inserta su voz en la narración, véase Toro (1981) 
su sospecha de que don Manuel solamente "creyó no creer". La filantropía manifiesta del cura la lleva por este sendero tan contradictorio: ella piensa que alguien que amaba a las otras personas de la manera como el santo lo hacía estaba de hecho ejerciendo la práctica religiosa aunque se creyera ateo, y eso es ser más religioso que la gran mayoría, que dice serlo pero esto no se le traduce en actos a favor de los demás. Yo la corregiré: eso es ser un filántropo, no un religioso. La buena y simple Ángela no es capaz de notar la diferencia.

En cuanto al hermano de la narradora, Lázaro, es destacable que — siendo el único a la altura intelectual del cura—no tiene sin embargo una posición desde la cual lo pueda confrontar.

Muy pronto se deja convencer de los motivos y las bondades de don Manuel, y permite que este lo "resucite" de una manera muy distinta a como se resucitó al Lázaro bíblico: haciéndolo colaborar en su proyecto de promover tanto el engaño como la ayuda concreta. No hay, en esta narración, una verdadera oposición filosófica ante la postura del protagonista: Lázaro cede a toda velocidad (de América había vuelto con el afán de oponerse al poder del clero en la atrasada España, pero eso le dura lo que dura un lirio); Ángela no se da cuenta de las implicaciones y de las contradicciones de su mensaje (es una Ángela obtusa); Blasillo el bobo -y con este, el pueblo todo de Valverde de Lucerna se mantendrán el disfrute pasivo de la mentira piadosa que el cura les promulgó. Así se puede resumir, en una expresión gastada, la filantropía de este santo: una mentira piadosa.

\section{BERNARD RIEUX}

Si se pudiera llamar la atención por ser modesto, el doctor Bernard Rieux lo haría decididamente.El caso es que no se puede: ser modesto implica hacer un esfuerzo para no llamar la atención. Su decisión de narrar usando la tercera persona en lugar de la primera, nos da una poderosa señal en ese sentido; el doctor no quiere repetir la palabra "yo" (y recordemos que en francés el pronombre no se elide). Cuando, bien entrada la narración, el personaje admite que también es el narrador, lo hace luego de haber propuesto como "héroe del relato" a alguien más, como Joseph Grand, de quien dice: "Oui, il est vrai que les hommes tiennent à se proposer des exemples et des modèles qu'ils appellent héros, et s'il faut absolument qu'il y en ait un dans cette histoire, le narrateur propose justement ce héros insignifiant et effacé qui n'avait pour lui qu'un peu de bonté au cœur et un idéal apparemment ridicule." (Camus, 1982, p. 129) ¿Aparentemente ridículo? Se queda corto el buen doctor: Grand es decididamente ridículo, en especial en lo concerniente a este ideal: el de escribir una novela de la que tiene ensayada la primera oración un número tan grande de veces que llena cuadernos enteros, sin avanzar jamás de ahí, pues está decidido a que, cuando el hipotético editor la lea, este deba levantarse y decir: "Messieurs, chapeau bas"12. Pero este aspecto risible es lo que Rieux rescata en los héroes, tales como él los ve: personas que están lejos de constituir un espectáculo para que los admiren, sino simplemente seres humanos vulnerables, torpes, cómicos. Es imposible dejar de pensar en el bueno de Alonso Quijano, que, como Joseph Grand, padece una obsesión ridícula de origen literario, y que — como él— va tras el bien, pero sin desprenderse jamás de esa obsesión personal y hasta un poco egoísta.

Con esta artimaña, Rieux consigue eludir él mismo el papel de héroe. La razón es profunda: en su modestia, el doctor solamente toma el mérito por estar haciendo su trabajo. Ejecutarlo diariamente, sin detenerse a pensar demasiado, le garantiza el papel marginal que quiere para su vida. Ni siquiera como médico aspira Rieux a producir conocimiento profundo; lo suyo es la atención de las necesidades de sus pacientes, de una forma casi más cercana a la que tendría un enfermero que un médico. Es otro doctor, el viejo Castel, quien investiga: "Rieux attendait les vaccins et ouvrait les bubons. Castel retournait à ses vieux livres et faisait des longues sessions à la bibliothèque."(Camus, 1982, p. 62).

Así, Rieux renuncia a la filosofía. Al menos, a cierta clase de ella: la que pretende tener respuestas abstractas y definitivas. Lo suyo es emprender una labor de hormiga incansable y esto lo identifica con la honestidad, pero solamente en su caso particular. Cuando Tarrou le pregunta por esta, él le responde: "Je ne sais pas ce qu'elle est en général. Mais

\footnotetext{
12 Rieux se muestra desde el principio escéptico: en primer lugar, porque le parecería extraño que un editor estuviera trabajando con el sombrero puesto. Humor camusiano.
} 
dans mon cas, je sais qu'elle consiste à faire mon métier."(Camus, 1982, p. 151). Ni siquiera se pretende especialmente virtuoso por haber elegido la medicina, pues lo hizo obedeciendo a su deseo de superarse, nacido en una familia pobre. El filántropo camusiano por excelencia este modesto doctor Bernard Rieux cuando es forzado a filosofar, porque a su alrededor le hacen preguntas o porque prevé que los lectores se las están formulando, reitera una filosofía que rehúye toda abstracción. Se resume en una negación: "L’homme n'est pas une idée..." (Camus, 1982, p. 51). Como el hombre no es una idea, hay que anteponer el hombre a las ideas: estas jamás serán tan importantes como aquel.

El personaje llega incluso a sostener una suerte de relación de exclusión entre el conocimiento y el cuidado de los seres humanos. El ejercicio de la filantropía concreta, en el día a día, implica la posposición del pensamiento. Para ejercerlo, hay que disponer de un tiempo precioso, del cual un médico - pero acaso, cualquier ser humano sensible ante el dolor y la necesidad ajenos-no dispone: "Ah!, dit Rieux, on ne peut pas en même temps guérir et savoir. Alors, guérissons le plus vite possible. C'est le plus pressé."(Camus, 1982, p.191).

La prisa por curar a los enfermos de la peste se impone por sí sola. No necesita de una sesuda discusión previa. La solidaridad ante el sufrimiento es un asunto para Rieux de mero sentido común, no de filosofías. Se puede objetar (y así se ha hecho; discúlpeme el lector que no dé las referencias, pero me niego a dar crédito alguno a una opinión que encuentro tan mezquina) que el protagonista de $L a$ peste exhibe la misma profundidad filosófica que la Cruz Roja. Yo quisiera ver quién está dispuesto a menospreciar a la Cruz Roja el día que la necesite.

Por esta misma premura para ayudar, Rieux se ve obligado a prescindir del amor hacia alguien en particular. Su esposa se enferma y debe salir en procura de tratamiento poco antes de que se declare la peste. Luego las puertas de la ciudad de Oran se cierran, por lo cual Rieux se ve imposibilitado para reunirse con ella. Muere sola, en un sanatorio. Se puede pensar que no estaba en manos del doctor el acompañarla, pero hay otro personaje en la novela, Rambert, que hace todo lo posible por escapar de la ciudad para ver a la mujer amada. Rieux ni si- quiera lo considera. Rambert no lo consigue, y hasta cambia de opinión ante el ejemplo de la actitud de Rieux. Sacrificar la felicidad personal en procura del bien común es una tarea urgente, ineludible.

Viendo los cambios dados en un personaje como Rambert, se podría pensar que Rieux exhibe un poder de convencimiento importante. Tal vez así sea, pero Rieux no predica. Todo lo que los demás personajes aprenden de él, lo aprenden por el ejemplo. Rieux tampoco juzga. De hecho, el personaje que le resulta más incomprensible al doctor no es el cura Paneloux, que anuncia con retórica atronadora en el púlpito que la peste viene como castigo del cielo a los pecadores. Rieux simplemente piensa que el cura no ha tenido suficiente contacto con el sufrimiento real de los seres humanos y por eso puede pensar así. La mucha teología y la poca experiencia le han jugado una mala pasada.

Al pasar un tiempo y vivir entre enfermos reales, $\mathrm{Pa}-$ neloux cambia y hasta se incorpora a quienes combaten la peste en el día a día, junto al doctor. Esto le demuestra a Rieux que él tenía razón (por supuesto, el doctor no se ufana de ello). El personaje que menos comprende el doctor Rieux es el del juez Othon, porque este sí que ha tenido contacto con las personas y aun así insiste en sus autoritarismos ${ }^{13}$. Alguien que dedica su vida a ejercer la certeza acerca del bien y del mal así como a imponer esa certeza a los demás, le resulta completamente opaco al doctor, que no por eso lo juzga y condena. Como el juez también se convierte en una víctima de la peste, al morir su hijo pequeño, Rieux manifiesta su deseo de ayudarlo a él como lo ha hecho con otros, pero se queda varado en la pregunta sin respuesta de cómo se puede ayudar a un juez. Para Rieux, es evidente que no hay que juzgar, pues cada cual tiene una tragedia incomunicable en su interior y solamente podemos aspirar a curar sin juzgar. Aquí también diría el doctor: "C'est le plus pressé"14.

Otros dos personajes interesantes están alrededor de Bernard Rieux y quisiera referirme brevemente a ellos, pues los he pasado por alto y lo cierto es que

13 Curiosa coincidencia la de este nombre y el de cierto político costarricense, también muy dado a juzgar. ¿Lo habrá elegido Camus pensando en la etimología? Otón quiere decir "dueño de señorío".

14 No es cita, sino deducción. 


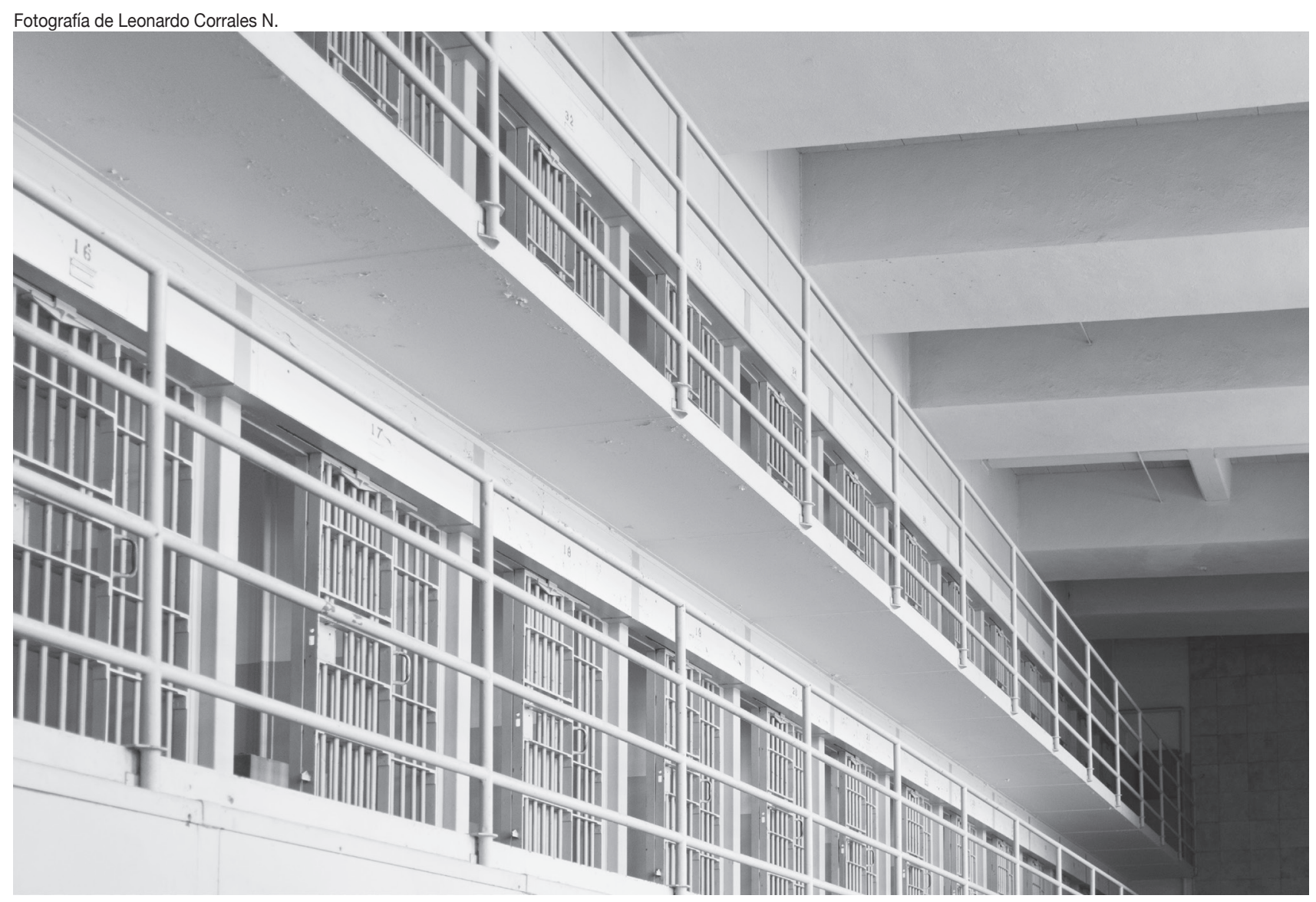

completan la red de relaciones concreta en que se mueve el doctor. Tarrou es un tipo que, desde el más profundo escepticismo hacia la existencia de Dios, aspira sin embargo a ser un santo. No solamente esto es notable en él, sino además el hecho de que su primera actitud ante el mundo es de indiferencia total, por razones filosóficas fácilmente ubicables dentro del pensamiento de Camus. Tarrou es uno más de los personajes camusianos desengañados acerca de un posible sentido de la existencia. Vive en el absurdo. Su actitud, en consecuencia, es de distanciamiento hacia todas las formas de la ilusión existentes acerca del significado de la vida. Pero Tarrou cambia en cuanto aparece la peste, pues la fuerza de los acontecimientos le enseña que la indiferencia es un lujo que no nos podemos permitir ante el sufrimiento ajeno. Por eso pretende ser un santo, convencido como está que la inexistencia de Dios le quita todo posible sentido a la existencia humana. Cuando Rieux le responde que en cambio él solamente aspira a ser un hombre, en lugar de un santo, Tarrou hace una declaración notable: "Oui, nous voulons la même chose, mais je suis moins ambitieux." (Camus, 1982, p. 230) Según él, resulta más sencillo ser un santo que ser un hombre: esto se puede interpretar como que el santo ha renunciado a buena parte de la complejidad propia del ser humano; un santo es menos que un hombre.

Exactamente en las antípodas éticas de Bernard Rieux, se encuentra Cottard. Lo primero que sabemos es que este individuo trata de suicidarse antes de que se desate la peste. Luego, nos enteramos de que ha cometido algún delito y la policía se halla tras él. Cuando el estado de emergencia se declara, las autoridades tienen nuevas preocupaciones y se olvidan de su delito. Entonces resulta que Cottard se alegra por la venida de la peste, la cual además le permite enriquecerse mediante el contrabando en la ciudad llena de desabastecimientos. Es el ejemplo más claro de egoísmo indisimulado: Cottard teme el fin de la peste que el flagelo se acabe porque eso implicaría que él volvería a estar en peligro ante la policía, así como el fin de sus negocios turbios. Casi no hay nada más que agregar a este retrato de un individuo tan falto de ética, salvo el hecho de que 
Rieux declina juzgarlo también a él. El filántropo camusiano no hace excepciones ante la regla de abstenerse de juzgar a los otros ${ }^{15}$.

\section{COMPARACIÓN Y CONCLUSIONES ${ }^{16}$}

Tanto Rieux como don Manuel descreen de cualquier tipo de trascendencia humana. Son filántropos sin motivación religiosa ${ }^{17}$. La vida se vive y se acaba de forma evidente con la muerte del cuerpo. Ahora bien, mientras que para don Manuel esto conlleva una profunda tristeza, una incapacidad insuperable de ser feliz; para Rieux parece no haber tiempo ni siquiera de hacer esta reflexión. Tarrou, su amigo, da la impresión de estar en este punto más cerca de don Manuel que Rieux. Don Manuel debe buscar tareas para no pensar todo el día en el sinsentido de una vida que se acaba con la muerte, mientras que Rieux no tiene ninguna necesidad de buscar ocupaciones, ya que estas lo persiguen: las enfermedades atendidas por un médico no acaban. Es interesante que, incluso cuando la terrible peste ha pasado, Rieux nos dice de sí mismo que sigue ocupado atendiendo otra clase de pacientes.

Ahora bien, Rieux no se encuentra en la misma página de desesperación de don Manuel, pues es un personaje capaz de darse la oportunidad para ser

15 Lo que me parece problemático en relación con esta actitud de Rieux excede los alcances de este ensayo, pero igual me permito plantearlo. Se trata de que La peste es una novela alegórica, en la que todos adivinamos expresada la experiencia de la guerra en la Francia tomada por el nazismo. Si Cottard representa al colaboracionista en esta alegoría, ¿todavía es posible abstenerse de juzgarlo? Quizás. Lo que sí es cierto es que no nos abstendríamos de juzgar a los invasores, los nazis, pero estos no aparecen en la alegoría camusiana: los reemplaza el bacilo de la enfermedad. ¿Estamos ante una velada estrategia para proteger a Rieux de emitir juicios acerca de las demás personas? ¿Qué hubiera tenido que decir el buen doctor si estuviera combatiendo seres humanos perversos en lugar de microbios?

16 En lo que compete propiamente a la comparación entre estos dos personajes, únicamente he encontrado aprovechables los planteamientos de Caraway (1995: 155): "In his basic understanding of the human problem, Unamuno's analysis is not unlike that of Camus who views man as having two existential longings, namely, the longing for absolute security in his being, immortality, and the longing for knowledge. For Camus, the world answers the first longing with death and the second longing with opacity. For Unamuno the first longing remains a longing throughout his life, hence the pervasive "agony," and the second longing, that is, the longing for knowledge, remains unfulfilled since reason is inadequate to establish the truth of man's ultimate concern". Como se ve, se trata de una comparación de carácter general, que no pone el énfasis en los personajes que estoy estudiando.

17 Con esto no quiero insinuar que los filántropos sean o hayan sido en su mayoría gente religiosa. Simplemente, señalo un rasgo. feliz con el disfrute de lo fugaz y lo inmediato que esta vida sin más allá nos ofrece. Esto queda magistralmente retratado en el pasaje en el cual el doctor y Tarrou se permiten un rato para tomar un baño en la playa. Lo que pasa, por consiguiente, es que Rieux antepone su sacrificio para atender el urgente sufrimiento ajeno a su capacidad para disfrutar de la vida breve y concreta, capacidad que sí posee, pero que no tiene muchas ocasiones de ejercer. Don Manuel, en cambio, no posee esta capacidad. De hecho, cuando don Manuel mira el agua del lago, no piensa en pasar un buen rato nadando, sino en suicidarse por inmersión.

Con Manuel encuentra en el ejercicio de la filantropía tanto una manera de contribuir a remediar el sufrimiento de los otros como el suyo propio, precisamente por lo explicado anteriormente. Es dedicado sin cesar a las labores de ayuda que consigue el personaje tanto el dar su colaboración como el olvidarse de su tristeza existencial. Rieux, en cambio, no anda buscando olvidar nada, y hasta está rechazando el dedicarse a su felicidad personal, a la que acaso tendría acceso, pero, por razones que ni él mismo comprende, la urgencia de ayudar se le impone. Sus palabras: "Rien au monde ne vaut qu'on se détourne de ce qu'on aime. Et pourtant je m’en détourne, moi aussi, sans que je puisse savoir pourquoi. "(Camus, 1982, p. 191). En este sentido, habré de plantear que la filantropía de Rieux es más meritoria que la de don Manuel, pues sacrifica la propia felicidad personal, si bien también la encuentro más oscura (lo mismo que el personaje), pues carece de explicación. Es simplemente algo que le ocurre al doctor, y que tal vez solamente responde a un caso concreto de la reflexión final del personaje: "...il y a dans les hommes plus de choses à admirer que de choses à mépriser." (Camus, 1982, p. 279). Con él, habría que invocar de nuevo a Machado y el secreto de la filantropía.

Otro punto de coincidencia importante en ambos personajes es su distanciamiento en relación con el pensamiento filosófico abstracto. Para ellos, el conocimiento que antepone ideas a experiencias concretas, está muerto. Si de palabras se trata, Rieux y don Manuel prefieren no abundar en ellas; si de hechos en procura de ayudar, entonces no son parcos. La motivación de don Manuel es que mucha 
filosofía lleva a cualquiera al abismo, pues por medio de la reflexión se descubre la terrible verdad de la muerte sin remedio. La de Rieux es diferente: el doctor intuye que el conocimiento nunca debería ocupar la atención que la urgencia de curar el sufrimiento inmediato y evidente requiere. Así pues, aunque por causas distintas, los personajes coinciden en negarse a vivir una vida de meros intelectuales.

Tanto Rieux como don Manuel rehúsan el papel de jueces. Ayudan a los demás sin juzgarlos, convencidos de que los seres humanos siempre sufren dolores que los reivindican. Quizá esta sea la característica más importante que los hace ser filántropos, pues sus antípodas, los misántropos, son primordialmente personas que se creen con la autoridad para juzgar y condenar a los demás. El misántropo es alguien que ha generalizado un juicio negativo sobre la humanidad, mientras que el filántropo (al menos, en los casos de Rieux y don Manuel) es alguien que no se atreve a juzgar a nadie. Como todos sufrimos, no hay quien pueda ser el juez para determinar qué sufrimiento justifica el accionar de alguien en particular y qué sufrimiento no lo justificaría. No es posible acceder al corazón de los otros para juzgarlos.

Tanto Rieux como don Manuel provocan cambios en la vida de las demás personas básicamente por medio del ejemplo. El discurso también cuenta, pero viene en un claro segundo lugar. Si bien don Manuel es un cura, y por tanto un predicador consuetudinario, sus prédicas rara vez hacen más que un llamado a vivir con sencillez y fe: es mucho más lo que enseña este sacerdote por la vía del ejemplo. Rieux, por su parte, como ya lo vimos, se rehúsa a predicar, lo que no impide que esta novela esté llena de sus apreciaciones éticas por lo general muy breves (no tiene tiempo el doctor para extenderse), en las que llama a priorizar en la atención del sufrimiento inmediato.

Por otro lado, Rieux y don Manuel carecen de adversarios filosóficos de mucho peso en sus textos. Don Manuel no tiene que realizar ningún esfuerzo para convencer a Lázaro, el único con alguna inteligencia, de que su camino es el correcto. En cuanto a Rieux, sí tiene más oposición, un poco en el escéptico Tarrou y mucho más en el enamorado Rambert
(Joseph Grand no es muy lúcido; es casi un Blasillo el Bobo). A los dos los convence con el peso de su ejemplo, casi sin tener que dar argumentos. De hecho, con Rambert el doctor insiste en darle la razón, pero luego la fuerza de sus acciones, empecinadas en ser solidarias, "desarman" a Rambert. Un punto importante por concluir es, entonces, que en estas narraciones se valora el ejemplo filantrópico antes que cualquier racionalización de la filantropía.

La mayor diferencia entre Rieux y don Manuel estriba en su relación con la mentira. Don Manuel ha decidido hacer del embuste su residencia permanente, por razones tanto filantrópicas como elitistas, mientras que Rieux mantiene un compromiso constante con la verdad. El doctor no miente, y quizá por eso una de las grandes debilidades de su labor filantrópica es que Rieux no ofrece consuelo ante la muerte. En algún momento, incluso se plantea que la llegada del doctor a la casa de un enfermo producía más dolor todavía, pues no ignoraban los familiares la probable condena de muerte que esta visita implicaba. Don Manuel está dispuesto a sacrificar también a la verdad en aras de aminorar el sufrimiento humano, y todo indica en el texto que así lo consigue; Rieux, por su parte, solamente está dispuesto a actuar honestamente: no se cree el doctor superior a nadie como para tratarlo como a un niño al que puede mentírsele. Rieux tampoco expresa tal deseo.

En cuanto a los resultados más generales de sus "gestiones filantrópicas", hay que decir que en ambos casos son modestos. Lo son por causa de la condición humana, que no deja a la felicidad la posibilidad de triunfos permanentes, ni siquiera prolongados. Lo son porque existe la muerte y esta gana al final la partida. Don Manuel solamente puede procurarles un rato de felicidad ilusoria a sus feligreses; el doctor solamente puede retardar un rato el momento en el que la parca se impone. Sí debe decirse que don Manuel se concentra en los logros emocionales, al darles la ilusión de la felicidad a quienes son el objeto de su amor; mientras que Rieux se concentra en los logros corporales, imprescindibles según él para que los demás existan. Es que el doctor le apuesta a la felicidad como una experiencia corporal, un bienestar ligado a los sentidos en primer lugar, mientras que don Manuel, sí 
asocia la dicha con un estado anímico primordialmente. Se resume el contraste con facilidad al recordar la anécdota: Rieux visita enfermos para tratar de sanarles el cuerpo, mientras que don Manuel lo hace para consolarlos ante el fin. Uno es un médico $y$ el otro es un sacerdote.

\section{REFERENCIAS BIBLIOGRÁFICAS}

Baah, R. (2003). Miguel de Unamuno and the Art of Apocopation. Revista Hispánica Moderna, 56 (1), 17-27.

Baker, A. (1991). The God of Miguel de Unamuno. Hispania, 74(4), 824-833.

Benítez, M. A. (1968). Miguel de Unamuno’s Quest for Fulfillment. Peabody Journal of Education. 45, (6), 335-339.

Camus, A. (1982). La Peste. Gallimard: Paris.

Caraway, J. E. (1995). The Problem of Faith and Reason in the Philosophy of Miguel de Unamuno. Mediterranean Studies, 5, 151-162.

Fagan, K. (2009). La libertad de conciencia en Miguel de Unamuno. Alpha, núm. 29, 291-301.

Godoy Gallardo, E. (2001). El trasfondo bíblico en "San Manuel Bueno, mártir". Revista Chilena de Literatura, 58,19-34.

Hochberg, H. (1965). Albert Camus and the Ethic of Absurdity. Ethics, 75 (2), 87-102.
Just, D. (2010). From Guilt to Shame: Albert Camus and Literature's Ethical Response to Politics. MLN, 124 (4), 895-912.

Machado, A. (1999). Poesías completas. Edición de Manuel Alvar. Espasa - Calpé: Madrid.

Onfray, M. (2012). L'ordre libertaire. La vie philosophique d'Albert Camus. Flammarion, Paris.

Peyre, H. (1958). Albert Camus, an Anti-Christian Moralist. Proceedings of the American Philosophical Society, 102, (5), 477-482.

Tamayo Ayestarán, A. (2001). Nietszche en Miguel de Unamuno. El ciervo, 50 (600), 34-36.

Todorov, T. (1991). Crítica de la crítica. Trad. de José Sánchez Lecuna. Editorial Paidós: Barcelona.

Toro, F. (1981). Personaje autónomo, lector y autor en Miguel de Unamuno. Hispania, 64 (3), 360366.

Unamuno, M. (1987). San Manuel Bueno, mártir y tres historias más. Espasa-Calpé: Madrid.

Vega, J. M. y Carbonell, N. (1998). La literatura comparada: principios y métodos. Gredos, Madrid.

Víquez, A. (2016). Los misántropos de Camus y Greene: Calígula y el Dr. Fischer. Revista Comunicación, 37 (25), 2, 14-23. 